\title{
"The door has opened": moving forward with menstrual health programming in Bangladesh
}

\author{
Siobhan Warrington, Mimi Coultas, Mitali Das and Effat Nur
}

Siobhan Warrington is based at the Oral History Unit and Collective, Newcastle University, Newcastle upon Tyne, UK. Mimi Coultas is based at the Sanitation Learning Hub, Institute of Development Studies, University of Sussex, Brighton, UK. Mitali Das is based at Pure Earth, Dhaka, Bangladesh. Effat Nur is based at Plan International Bangladesh, Dhaka, Bangladesh.

Received 27 November 2020 Revised 20 April 2021 10 July 2021

Accepted 21 July 2021

(c) Siobhan Warrington, Mimi Coultas, Mitali Das and Effat Nur. Published by Emerald Publishing Limited. This article is published under the Creative Commons Attribution (CC BY 4.0) licence. Anyone may reproduce, distribute, translate and create derivative works of this article (for both commercial and non-commercial purposes), subject to full attribution to the original publication and authors The full terms of this licence may be seen at http:// creativecommons.org/ licences/by/4.0/legalcode

The authors acknowledge the important contribution of those interviewed in 2020 to support the development of this article. The authors also acknowledge colleagues who provided valuable comments on early drafts of this case study.

\begin{abstract}
Purpose - In Bangladesh, as elsewhere, menstruation is surrounded by stigma, silence, and shame. Despite being a critical part of women's and girls' sexual and reproductive health and rights (SRHR), it remains significantly under-researched and addressed. However, the focus on menstrual health $(\mathrm{MH})$ programming is growing globally, with increased awareness of the importance of holistic and rights-based approaches. This case study aims to examine and reflect upon the MH landscape and programming in Bangladesh, assessing the progress, challenges, and potential ways forward.

Design/methodology/approach - This case study is based on a non-systematic review of recent global and national literature, eight semi-structured interviews, a review of national television adverts and the authors' experiences of MH research and programming in Bangladesh.

Findings - Hygiene-based education delivered through schools is a common entry point for $\mathrm{MH}$ programming in Bangladesh, with limited activities conducted in communities (including with men and boys) and through media. The focus of $\mathrm{MH}$ programming has tended to be narrow, with insufficient recognition of the wider gender equality and health implications of menstruation. There are growing efforts to coordinate MH work by different agencies and to collectively advocate for increased government engagement. While significant progress has been made, this case study identifies several gaps and tensions that reflect the complexity of addressing $\mathrm{MH}$.
\end{abstract}

Originality/value - This case study presents an overview of recent MH experiences and programming in Bangladesh. It recognises the different sectors, sites and stakeholders involved, and includes experiences and perspectives of practitioners, academics, and programme participants.

Keywords Bangladesh, Gender, Women's health, Menstrual health, Menstruation

Paper type Case study

\section{Introduction}

Half of the global population will menstruate for a significant portion of their lives, yet around the world this normal and natural process is surrounded by stigma, shame and silence. Despite being a critical part of women's and girls' reproductive health, menstruation remains significantly under-researched and addressed (Bobel, 2020). The last decade, has, however, seen menstruation gain increasing recognition within research, programming, and policy. The United Nation's (UN) Special Rapporteur on the Human Rights to Water and Sanitation first began to consider menstruation under the remit of water, sanitation and hygiene (WASH) following a visit to Bangladesh in 2009. She explains: "my visit to Bangladesh informed the rest of my mandate in terms of the needs of menstruating girls and women, not just in schools but across all aspects of their lives, at home, in the workplace and beyond. Menstrual hygiene and health became an additional consideration to be included within the requirements of the human right to sanitation" (Roaf and de Albuquerque, 2020). Menstrual health has since been included in UN resolutions relating to the right to water and sanitation. For example, in 2018 the Human Rights Council called 
upon states to: "address the widespread stigma and shame surrounding menstruation and menstrual hygiene by ensuring access to factual information thereon, addressing the negative social norms around the issue and ensuring universal access to hygienic products and gendersensitive facilities [...]" (UN General Assembly, 2018). Menstrual health is also recognised as key for women and girls to realise many other rights, including the rights to health, education, work, and non-discrimination and gender equality (Human Rights Watch and WASH United, 2017). However, menstruation is often still viewed in sector siloes rather than from a rights-based, menstruator-centric perspective (Global South Coalition for Dignified Menstruation, 2020), and holistic approaches to improving menstrual health $(\mathrm{MH})$ are lacking. Much remains to be done to improve the experiences and rights of those who menstruate everywhere. This case-study examines and reflects upon menstruation-related programming in Bangladesh to review the progress, challenges, and potential ways forward.

\section{Methodology}

This case study is shaped by feminist research principles (Letherby, 2003; Leavy and Harris, 2019). We are a team of Bangladeshi and UK authors with diverse $\mathrm{MH}$ research and programming experience in Bangladesh, with specialist expertise in: participatory research; gender; WASH; and behaviour change communication. As feminist researchers we draw on different sources of knowledge, including our own, with an awareness of our own different positionalities. We adopt a holistic position on $\mathrm{MH}$ that centres the multiple priorities and needs of girls' and women to surface challenges, but also identifies ways forward for learning and programming on $\mathrm{MH}$ in Bangladesh.

This case study is based on a non-systematic review of the global and national literature, semi-structured interviews with a small cohort of professionals and experts by experience, and a review of a sample of television adverts for menstrual hygiene products. We adopted an inductive and iterative approach to data collection and analysis. Our review of the literature informed the question areas for our interviews, and findings from the interviews informed further literature searches for the purposes of corroboration. Interviews with rural women highlighted the significance of mass media on awareness and attitudes towards menstruation which led us to undertake a review of a sample of TV adverts. The reflections on $\mathrm{MH}$ programming in Bangladesh presented in this case study emerged and developed through regular collective analysis sessions between the authors.

Twenty-six peer-reviewed papers and book chapters (14 specific to Bangladesh), and 20 grey literature documents (10 specific to Bangladesh) were reviewed, prioritising literature published from 2016 onwards. Our inclusion of grey literature reflects a recognition that agencies leading $\mathrm{MH}$ programming in Bangladesh have undertaken relevant research which is often rigorous but not published in peer-reviewed journals. Thirteen Bangladeshi television adverts for disposable sanitary pads (broadcast 2017-2020) by five leading brands were also reviewed.

Interviews were conducted with four $\mathrm{MH}$ practitioners in Bangladesh (two based in nongovernmental organisations (NGOs), one in a donor agency, and one in a UN agency) and with four women engaged in Plan International Bangladesh's MH programming in Bhola district. These eight interviews served to broaden the authors' knowledge of $\mathrm{MH}$ programming in Bangladesh and incorporate the perspectives and expertise of those involved, as both participants and implementers. Interviewees were identified through the authors' networks and were chosen to bring out diverse perspectives and experiences. Key interview topics included: changes in the experience of menstruation and $\mathrm{MH}$ programming; the $\mathrm{MH}$ needs, priorities and challenges for women and girls; and knowledge and opinions on current programming and policy in Bangladesh, in terms of progress, gaps, and challenges. All interviews were conducted via telephone, in line with good research practice during the Covid19 pandemic. Participant information sheets were shared and discussed with interviewees before gaining their consent to participate. Written consent was obtained from the $\mathrm{MH}$ 
practitioners, verbal consent from the rural women. Interviews were recorded and detailed notes produced, including direct quotations.

Interview notes were coded to identify emerging themes. Analysis was collaborative and iterative: themes emerging from the interviews (and literature) were reviewed and discussed during several remote analysis sessions, followed by further meetings and communication between the authors to support continued reflection and write-up.

\section{Limitations}

This case study focuses on the menstrual experiences of, and programming directed at, ablebodied women and girls. The authors recognise that people who menstruate also include those with disabilities, transgender men, and those who identify as non-binary. The authors are also aware that women and girls in Bangladesh have multiple, and intersecting identities which create distinct menstruation experiences and needs relating to their socio-economic status, place of residence, and religion, for example. Exploring the full diversity of menstruation experiences and needs within Bangladesh is beyond the scope of this case study. This case study is based on a relatively small number of interviews with $\mathrm{MH}$ practitioners and programme participants. It is also important to note that we did not formally critically appraise the literature reviewed.

\section{Terminology}

We recognise that Menstrual Hygiene Management (MHM) remains the most commonly used term for menstruation-related programming in Bangladesh. Within this article, we have chosen to use the term Menstrual Health $(\mathrm{MH})$, recognising the importance of considering menstruation in its broadest sense.

At the time of finalising this case study (April 2021) The Global Menstrual Collective Terminology Action Group published a new definition of $\mathrm{MH}$ that draws on past work and input from expert stakeholders: "Menstrual health is a state of complete physical, mental, and social well-being and not merely the absence of disease or infirmity, in relation to the menstrual cycle." (Hennegan et al., 2021). This definition, and the requirements set out to achieve $\mathrm{MH}$, align with the authors' holistic position on $\mathrm{MH}$ adopted for this case study.

\section{Findings}

\section{Overview of the menstrual health landscape in Bangladesh}

Despite significant improvements in maternal health and gender parity in school enrolment, discrimination and gender-based violence remain major challenges for women and girls (Bangladesh Bureau of Statistics, 2016). Bangladesh has the fourth highest prevalence rate of child marriage in the world, with $59 \%$ of girls getting married before the age of 18 (National Institute of Population Research and Training and ICF, 2019).

From menarche to menopause, many women and girls in Bangladesh experience harmful norms and beliefs, stigma, and taboo linked to their menstruation (Mondal et al., 2017; Zakaria et al., 2020; Guglielmi et al., 2020; Power et al., 2020). These include restrictions to their diet and movement, pressure to hide their menstrual status, limited access to information and healthcare relating to menstruation, and increased risk of child marriage following menarche.

The 2014 Bangladesh National Hygiene Baseline Survey quantified MH needs, providing justification and momentum for investment in $\mathrm{MH}$. The survey found that $82-86 \%$ of women and adolescent girls use old cloths to manage their menstruation; $25 \%$ of students do not go to school during menstruation; and only $36 \%$ of students know about menstruation before menarche (ICDDR, 2014). 
$\mathrm{MH}$ programming in Bangladesh appears to be predominantly led by national and international NGOs, many of which approach it from either a WASH or sexual and reproductive health and rights (SRHR) perspective. WASH-oriented interventions typically include education around ways to manage menstruation hygienically, and provision of the facilities and materials needed for this. SRHR-oriented interventions focus on menstruation as a part of puberty education (International Women's Health Coalition, 2019). Recent initiatives (for example the Ritu programme by Simavi, and a programme coordinated by Bangladesh Nari Progati Sangha (BNPS)) are however adopting a broader, multi-sector approach. The MHM (Menstrual Hygiene Management) platform has also been established, to coordinate the efforts of those working on $\mathrm{MH}$ - including private sector representatives.

At a government level, $\mathrm{MH}$ falls across several departments, including education, women and children's affairs, health, and rural development. MH activity is increasing across these, including through government-NGO partnerships. Significantly, and linked to advocacy by the MHM platform, the government is currently working towards a National Menstrual Health Strategy. Members of the MHM platform have also provided technical input to include $\mathrm{MH}$ in the secondary school curriculum and teacher training materials.

\section{Menstrual health programming in Bangladesh: progress, gaps, and challenges}

In this section we examine three aspects of $\mathrm{MH}$ programming in Bangladesh that emerged from our review of the data: the different sites of programming; the different foci of programming; and the importance of stakeholders working together. Drawing on the literature reviewed, and interviews conducted, we present the progress, gaps, and challenges in relation to current $\mathrm{MH}$ programming in Bangladesh. Where relevant, we also consider global knowledge and experience.

\section{Sites of menstrual health programming}

Schools. MH programmes around the world often target schools with the aim of reaching adolescent girls (and boys) with improved information, products and facilities and reducing girls' absenteeism (Hennegan, 2020). Schools are a common entry point for both government and NGO MH work in Bangladesh. In 2015 and 2019 the Government of Bangladesh (GoB) issued circulars regarding sanitation improvements in schools, these included the provision of female-friendly toilets and sanitary pads, and the requirement for teachers to discuss menstruation with female students. NGO projects, (for example, those run by WaterAid, WASH United, and Simavi) have had a similar focus with some also building schools' capacity to sustain this work, training teachers on how to run menstruation education sessions and working with school management on the maintenance of menstrual-friendly toilets.

One of the $\mathrm{MH}$ practitioners interviewed explained that although the topic of menstruation is included within a school textbook, in practice "teachers do not teach that chapter in the classrooms, so children do not get proper information and they grow up with misconceptions". This may be exacerbated by a lack of female teachers, particularly in secondary schools: in 2015 only $25.8 \%$ of secondary teachers were female (Bangladesh Bureau of Statistics, 2017). Even where $\mathrm{MH}$ is taught, there is evidence to suggest that school-based interventions often do not target girls early enough. Data from 2014 found that $66 \%$ of girls are unaware of menstruation before they reach menarche (ICDDR, 2014). The Ritu programme sought to address this limitation, by targeting pupils aged 10-13 years (Simavi, 2020) but this approach does not yet seem to be widespread in Bangladesh.

The emphasis on schools as a site of intervention inevitably means that girls who are out of school are not reached. It also excludes women, ignoring their own needs and leaving mothers and elder sisters without accurate information, despite their recognised role in supporting their daughters and younger sisters to understand and navigate menarche 
(Erchull, 2020; Chandra-Mouli and Patel, 2020). As one MH practitioner described: "mothers didn't know how to address their sufferings but now [...] they want to know about menstrual health to ensure that their [daughters] do not face the same challenges". A recent report by WaterAid and Marie Stopes (Water Aid, Marie Stopes International Australia, 2018) also recognises women as significant $\mathrm{MH}$ educators stating, "[...] it is critical for education programs to address intergenerational gaps in knowledge and information".

Communities and workplaces. Some programming (for example, by Plan International Bangladesh and Simavi) has broadened its scope to reach people beyond the school setting, recognising the importance of building an enabling and supportive environment that extends to homes, communities and workplaces.

Community-based activities typically seek to engage women and girls and include $\mathrm{MH}$ education sessions, methods to manage menstruation (for example the local manufacture of sanitary pads), and the construction of menstrual-friendly toilets. Two of the $\mathrm{MH}$ practitioners interviewed also described initiatives specifically targeted at those working in garment factories, with one highlighting the effectiveness of a programme combining awareness-raising for workers, and advocacy among factory owners for more menstrualfriendly working conditions.

There is a strong rhetoric around the importance of involving men and boys in $\mathrm{MH}$ programming, both in Bangladesh and globally (Erchull, 2020; Fahs and Perianes, 2020). The $\mathrm{MH}$ practitioners and rural women interviewed echoed this. One MH practitioner noted "men and boys have responsibilities in breaking taboos", while the rural women outlined the benefits of men's increased awareness of $\mathrm{MH}$, including their ability to request husbands to purchase sanitary pads. The $\mathrm{MH}$ practitioners interviewed reflected on the challenges of engaging with men who are often away from home, having migrated elsewhere for work.

Media. With over $80 \%$ of Bangladesh's population regularly watching television (European Journalism Centre, 2021), this medium provides an opportunity to extend $\mathrm{MH}$ campaigns to mass audiences, beyond face-to-face initiatives. In 2016, Shorno Kishoree Network Foundation and the Ministry of Women and Children Affairs of the GoB launched Din Bodole Amra, the first TV series in Bangladesh to focus on $\mathrm{MH}$. The Ritu programme launched its own TV series Best School for Girls in 2017. Television adverts for sanitary pads have a similar reach. Our review of 13 adverts by leading brands found the majority were contributing to the agenda to normalise menstruation by showing open discussion about menstruation within households and schools. Some also showed how brothers, fathers and husbands can play supportive roles, including for example, purchasing pads. The majority of the TV adverts also link the use of pads with hygiene messaging and increased freedom for women and girls. Eight of the adverts included imaging to demonstrate absorbency of the pads relating to increased confidence for women and girls.

Online platforms and social media are also a way for $\mathrm{MH}$ campaigns to extend their reach. The Ritu programme, for example, launched a multi-media campaign using Facebook, and an online knowledge platform in addition to its TV drama.

\section{Focus of menstrual health programming}

Hygiene and materials. In Bangladesh, as in many other countries, WASH actors were early champions of $\mathrm{MH}$ (Miller and Winkler, 2020). This is likely to have contributed to the common focus on hygiene as an entry point for $\mathrm{MH}$ programming, in relation to knowledge and behaviour change, as well as the provision of facilities and materials. Much of the information currently shared through $\mathrm{MH}$ programmes - in schools or other sites - is focused on the practical means of managing menstruation hygienically. All four women interviewed for this case study described, unprompted and in detail, the practical steps they, and others, take to manage their menstruation. 
There has been an emphasis on the use of sanitary pads from all actors (NGO, government and private), with some programmes supporting the manufacture and distribution of these, and/or promoting their use. Advertisements for disposable sanitary pads have typically promoted these by contrasting them with the use of re-useable cloths (sometimes referred to as 'rags') as inherently unhygienic. Some academic articles on $\mathrm{MH}$ in Bangladesh take a similar position in asserting that the use of cloths is unhygienic (Mondal et al., 2017; Zakaria et al., 2020; Sultana et al., 2020; Asha et al., 2019).

Despite this, MH practitioners interviewed, and several recent studies (Alam et al., 2018; Alam et al., 2017) describe the use of cloths to absorb menstrual blood as widespread in Bangladesh. The women interviewed for this case study referred to the use of pads being more popular with girls than women, who continue to use cloths. These interviews also revealed that girls make strategic choices about the choice of materials; using pads when they go to school, due to their greater absorbency, and more affordable cloths when they are at home. The generational difference in preference of materials was also apparent in formative research conducted by Plan International Bangladesh in 2016 (Warrington and Martin, 2017).

In 2020 a systematic review of studies of $\mathrm{MH}$ intervention experiences in six countries revealed that comfort and containment were most highly valued in relation to new menstrual products (Shannon et al., 2020). These were also key design features that mattered to adolescent girls who participated in the research by Plan International Bangladesh in 2016 (Warrington and Martin, 2017). However, priorities and patterns of use may have changed during Covid-19. According to interviews with $\mathrm{MH}$ practitioners and a WaterAid report (2020), the use of disposable pads has decreased during Covid-19 for reasons of inaccessibility and unaffordability. This suggests that messaging on how to best wash, dry and replace cloths to ensure these cloths do not pose a risk to infection remains relevant. It also highlights the importance of women and girls having a choice of menstruation materials and of listening to their different needs and priorities, in relation to the challenges they face and the choices they desire (Perianes and Roberts, 2020).

Disposal Disposal issues related to single-use sanitary pads are increasingly being acknowledged, both in Bangladesh and globally (Simavi, 2020; Perianes and Roberts, 2020; Hennegan, 2020; Miller and Winkler, 2020). Three of the four MH practitioners interviewed also raised this as a priority area moving forward. The interviews with women conducted for this case study suggest that common practice is to bury (or burn) used sanitary pads; yet increasing demand for disposable pads poses a significant environmental burden for Bangladesh. In Cox's Bazar, where high population density and frequent mud slides mean burying used disposable sanitary pads would be highly problematic, NGOs have distributed re-useable red cloths to women and girls (WASH Sector Cox's Bazaar Inter Sector Coordination Group, 2020). There are also a small number of initiatives producing and promoting the use of reusable pads, for example social enterprise Wreetu. As part of the Ritu programme, a Dutch research organisation has also collaborated with a leading producer of sanitary pads to develop a biodegradable plastic layer for disposable pads (Simavi, 2020).

Menstruation-related health issues Menstrual hygiene, materials, and disposal, are, not the only aspects of $\mathrm{MH}$ that need to be addressed in order to enable women and girls to safeguard their SRHRs. The MH practitioners interviewed, reflected on the importance of broadening $\mathrm{MH}$ education beyond practical management and addressing other aspects of $\mathrm{MH}$, as well as linking it with wider SRHR curricula and initiatives focusing on gender empowerment and norm change. Interviews with $\mathrm{MH}$ practitioners suggest that pain management, the impact of hormonal changes, menstruation over the life course, and the psychosocial aspects of menstruation are all areas currently absent from the majority of $\mathrm{MH}$ programming in Bangladesh.

As one $\mathrm{MH}$ practitioner interviewed noted "There is a pain management issue. A lot of women go through severe pain and a lot of other complications, but such things are not addressed in 
the programmes". Of the reasons given for missing school in the Ritu programme's baseline survey, cramps/bad physical feeling was reported by $64 \%$ of girls who missed school last time they menstruated (Simavi, 2020). Pain was also identified as a key challenge by adolescent girls in the Plan International Bangladesh research (Warrington and Martin, 2017) and by all four women interviewed for this case study. Despite noting the importance of seeking medical care from doctors for some menstrual issues, such as irregular periods, the women interviewed explained that many women and girls seek remedies from kabiraj (spiritual healers) when dealing with pain. These remedies include drinking holy water blessed with verses from the Quran, adherence to dietary restrictions and restricting movement outside whilst menstruating to avoid the evil eye or evil spirit, particularly in the evening.

With few references to pain in the literature, there appears to be little support for women and girls to manage menstrual pain medically, either in Bangladesh or globally. Power et al. (2020) share findings of qualitative research in Bangladesh with adolescent girls with cerebral palsy and their mothers, which refers to physical exercise as a low-cost and appropriate menstrual pain management strategy. While focused on disabled girls, its recommendation, "research from the global south exploring low-cost and culturally acceptable strategies to reduce menstrual pain such as exercise-based interventions are urgently needed [...]" has a broader relevance. MacRae et al. (2019), notes the lack of research in this area, particularly in low- and middle-income countries and warns that those working in MH should not "contribute to the silencing of women's pain", rather there is a need to include menstrual and material-induced pain in a revised definition of MHM as a "way of signalling that these concerns are being heard and are worthy of addressing."

The consideration of menstrual experience beyond menarche is also absent from $\mathrm{MH}$ programming in Bangladesh and elsewhere. The literature suggests that $\mathrm{MH}$ interventions tend to focus narrowly on physical changes experienced during puberty without putting this into a wider context of hormonal and physical changes experienced over the life course from menarche to menopause (Fahs and Perianes, 2020; Patkar, 2020). This was also noted by $\mathrm{MH}$ practitioners interviewed. This narrow lens ignores the numerous physical and mental biological changes, relating to menstruation, which women and girls can experience throughout their lives - heavier bleeding, gastrointestinal problems, depression - and the impact these have on their lives.

Addressing stigma The $\mathrm{MH}$ practitioners interviewed described the foundational importance of tackling shame and stigma within $\mathrm{MH}$ programming to create a more supportive environment for menstruators. One MH practitioner explained that "breaking the taboos is important before sharing any knowledge". Unless the silence surrounding menstruation is addressed, programmes across different sites and focal areas will make limited progress.

There have been multiple actors - government agencies, mass media, sanitary pad companies, as well as NGOs - contributing towards challenging the silence and taboos and normalising menstruation. The women interviewed in 2020, all of whom have engaged with Plan International's MH programming in Bhola, noted the following changes in their communities:

In the past, girls were told to stay at home, stop playing and prohibited from cooking.

Previously, girls and women were prohibited to eat fish, meat [...] but now there are no food restrictions, rather parents try to feed [their daughters] more nutritious food.

Now mothers are more conscious about menstruation and aware about their daughters and follow what is good for them.

The women interviewed attribute these changes to outreach work by various WASH facilitators, along with an increase in television content on $\mathrm{MH}$ (advertisements for disposable sanitary pads, dramas and public health content). 
However, further progress is needed to create a truly supportive environment in which women and girls can menstruate without risk of harm. As one of the $\mathrm{MH}$ practitioners interviewed recognised, "MH is not a separate thing [...] We have to connect it with all the components of empowerment and gender equality. Also, negotiation skills, raising voice, capacity of placing demand, capacity to claim demands - all these [...] will help to achieve the targets associated with menstrual health." Currently, there is a recognised risk of gender-based violence for girls and women who are menstruating. The women interviewed described the risk of genderbased violence for refusing to have intercourse whilst menstruating, while two $\mathrm{MH}$ practitioners noted menstruation-related risks of violence, for example towards girls outside the home if they are found to be menstruating. Beyond this, there also seems to be little acknowledgement in programming - in Bangladesh or globally - of the potential everyday stress (rather than physical violence) on women and girls of managing menstruation in a context of silence and shame (Chandra-Mouli and Patel, 2020; Hennegan, 2020). Indeed, Hennegan and Sol (2020) claim that the many psychosocial aspects of girls' menstrual experiences, including shame, fear and distress (and confidence) are missing from the research, warning that, "a myopic focus on hygiene risks minimising girls' lived experiences of menstruation if these constructs are not measured and prioritised in programme design and evaluation."

\section{Working together}

The growing momentum around $\mathrm{MH}$ in Bangladesh is increasing the emphasis on coordination. This is vital given the diversity of WASH, SRHR, gender, education and other stakeholders required to address $\mathrm{MH}$. The Ritu programme and the initiative coordinated by BNPS are examples of different stakeholders working together towards creating enabling $\mathrm{MH}$ environments in communities, as well as at local and national policy levels. (There is also significant cross-agency work and research on $\mathrm{MH}$ in Cox's Bazar.) The importance of government leadership and effective coordination of this complex and cross-cutting issue is also recognised in the global literature as necessary to encourage holistic rather than single-issue $\mathrm{MH}$ responses (Perianes and Roberts, 2020; Patkar, 2020; Hennegan et al., 2021).

To date, most MH interventions in Bangladesh have been led by NGOs working in specific geographies and on short timeframes. Geographic and time constraints limit the number of people they can reach and the changes they are able to affect given the time required to build trust and dialogue around taboo topics such as $\mathrm{MH}$. One practitioner stated, "[...] it is not easy to bring change in the norms within three to five years where the norms have been practiced for decades. We cannot expect that the harmful rituals women and girls have been following from their mothers or grandmothers will stop after attending two or three awareness sessions [...]". The women interviewed had similar concerns with one stating, "one session is not enough [for change to happen]".

As well as the need to coordinate, different stakeholders working on $\mathrm{MH}$ have much to learn from each other in this emerging field, and together have a stronger voice advocating for government leadership on $\mathrm{MH}$. In the words of one $\mathrm{MH}$ practitioner, "Collective advocacy is always effective." The MHM platform aims to encourage coordination and learning, and joint advocacy efforts for its 40 or so members to make clear and collective demands for government leadership on $\mathrm{MH}$ issues.

$\mathrm{MH}$ practitioners also reflected on the importance of engaging men at a policy level, noting that $\mathrm{MH}$ will struggle to gain traction at higher levels unless decision makers - who are predominantly male - are brought into $\mathrm{MH}$ discussions and understand how it affects their mandates. This was also noted by Patkar in her description of experiences introducing $\mathrm{MH}$ policy change in other countries across Africa and South Asia (Patkar, 2020).

Another area for better coordination across stakeholders relates to quality and alignment of monitoring, as without this it is hard justify continued investment. The Ritu programme made progress in this area with its intentional objectives to create robust evidence of impact to 
support further advocacy for investment in $\mathrm{MH}$ programming in Bangladesh. $\mathrm{MH}$ practitioners interviewed flagged that "the government must strengthen the monitoring side [of $\mathrm{MH}$ programmes]", and they pointed to the lack of evidence of the impact of interventions. This is recognised as a global gap (Hennegan, 2020; UNICEF, 2020) and remains, a critical area for the sector as a whole.

\section{Reflections: tensions and gaps}

Significant progress has been made in Bangladesh in recent years to improve the $\mathrm{MH}$ experiences of women and girls. Numerous national and international NGOs have championed the importance of $\mathrm{MH}$ to support women and girls to realise their rights to sexual and reproductive health. Private sector engagement is growing, and the issue is gathering momentum within government, with the development of a National Menstrual Health Strategy. One of the $\mathrm{MH}$ practitioners interviewed, remarked, "[...] the door has opened. People are talking about it, not only women but men are also getting involved, a policy is on the way to be developed [...]. The environment is much more positive if I compare it to five or 10 years [ago]."

In Bangladesh, as in many other countries around the world more remains to be done regarding the scope and scale of $\mathrm{MH}$ programming. With much of the current work focused on reaching adolescent girls and women with practical hygiene-related information, further work is needed to situate $\mathrm{MH}$ within broader conversations about gender equality, and women's sexual and reproductive health, well-being and rights over the life-course, from menarche to menopause. Understanding menstruation is an essential part of the knowledge women and girls need to make informed decisions about their bodies, particularly relating to their SRHR. Achieving good MH can also impact upon women's and girls' freedom, decision-making, earning opportunities, and ability to express themselves.

During our collective analysis of the literature, interviews, and review of TV advertisements, we identified several tensions relating to $\mathrm{MH}$ programming, which are outlined below. We do not believe these to be unique to the context of Bangladesh.

\section{Measuring qualitative $\mathrm{MH}$ outcomes}

Programming that is associated with the provision of knowledge, facilities (MHM-friendly toilets in schools for example), and access to materials is arguably easier to measure than slower and less tangible outcomes related to stigma and norm change, well-being, and gender equality. As the ability to measure and report on outcomes is a key consideration for both those allocating government budgets and those implementing projects, this can create a perverse incentive to avoid designing and funding truly holistic programmes. There is a need to design and embed monitoring and evaluation which can successfully measure less quantifiable outputs and outcomes for $\mathrm{MH}$ programming.

\section{Positive messaging and diverse experiences}

Another such tension lies between the positive messaging around menstruation as normal and natural (designed to address stigma and harmful norms, reduce school absenteeism and support girls to be physical), and the need to be attentive to the physical challenges menstruation presents for some women and girls. Women's and girls' experiences of menstruation and the related challenges and barriers they may face, are varied and not all will fit within a positive normalising framework. For example, some disabled women and girls will be unable to manage their menstruation independently, and for some women and girls (for example those with endometriosis), menstruation can be an excruciatingly painful and debilitating. 


\section{Unintentionally reinforcing stigma}

There is a risk that some of the hygiene messaging associated with $\mathrm{MH}$ (from advertisements, mass media, and NGOs) could (unintentionally) reinforce the belief behind many of the restrictions and taboos associated with menstruation, that menstrual blood is polluting or impure. This is true both in Bangladesh and globally (Johnston-Robledo and Chrisler, 2020). Advertisements for sanitary products that use a blue liquid in place of one more like blood reinforce the idea that menstrual blood should not be seen. Adverts also often show girls and women who use their products as active in the confidence that they will not be discovered as menstruating, suggesting that menstruation is something to be hidden.

\section{Choice of products and affordability}

Despite the increased availability of disposable sanitary pads, there is also a need to ensure that reusable cloths are not promoted as inadequate or inherently unhygienic given their widespread use. It is important to recognise that many women and girls have no feasible alternative to these. Women and girls should be supported to choose how to manage their menstruation, however, over-promotion of disposable alternatives as more hygienic or somehow better may in turn stigmatise or make people unnecessarily fearful of using reusable cloths. The use of reusable cloths and products is also important in tackling the environmental challenges presented by current disposal options.

\section{Address pain to counter harmful responses}

While progress is being made dispelling myths around menstruation-related restrictions from a hygiene perspective, women are still reporting the importance of following traditional pain management beliefs. Some of these relate to harmful myths and norms, which for example can restrict women's and girls' freedom of movement and diet. This points to a need to address menstrual pain within $\mathrm{MH}$ programming to provide women and girls with alternative responses to a recognised challenge they face.

\section{Engaging men and boys}

Finally, the engagement of men and boys in $\mathrm{MH}$ programming in Bangladesh, needs careful consideration. Some progress has been seen engaging men to encourage them to facilitate their family members' access to pads and medical care. However, by itself, this may perpetuate traditional roles where women and girls are dependent on men. Engagement with men and boys must tackle harmful attitudes and beliefs which are part of wider patterns of violence and discrimination against women and girls. The existing participation of boys in $\mathrm{MH}$ education within schools, could be used as an entry point for broader discussions relating to SRHR and gender equality.

\section{Moving forward}

This case study highlights the progress made with $\mathrm{MH}$ programming in Bangladesh and reveals some of the challenges and tensions in advancing this complex and important aspect of women's and girls' SRHR. Overall, it reflects an appreciation of the importance of a holistic and inclusive approach towards $\mathrm{MH}$ that:

- situates programming in multiple sites, and engages men and boys;

- addresses women's and girls' needs, experiences, and rights beyond hygiene and materials; and

- is a coordinated effort by NGO, government and private-sector actors. 
To inform the journey towards more holistic and inclusive $\mathrm{MH}$ programming in Bangladesh (and elsewhere), specific areas identified by this case study where further development and learning is needed include the following.

\section{Understanding and designing for different menstrual experiences}

Women's and girls' menstrual experiences are shaped by multiple intersecting identities and factors that also change over their life course. These need to be understood and better addressed in $\mathrm{MH}$ programming. Engaging with existing trusted representative groups such as disabled peoples' organisations - will be essential in order to reach, and work safely, and appropriately, with different menstruators. Ultimately, engaging menstruators themselves, to understand what shapes their menstrual experiences and priorities over their life course, and to co-design solutions is critical.

\section{Programming beyond hygiene}

Recognised gaps in current programming will require the development of new approaches to be developed and tested. These approaches should be shaped by better assessment of menstruators' needs and priorities (see above) but may include areas identified in this case study such as choice and satisfaction with menstrual products; disposal; pain; stress; violence; wellbeing; and menstruation-related health issues.

\section{Building an evidence base}

Monitoring and evaluation remains a critical area of improvement to address the breadth of $\mathrm{MH}$ programming. For example, while efforts are underway to address shame and stigma, there is little published on the effectiveness of different approaches to this. New indicators also need to be developed, tested and adopted for the areas of $\mathrm{MH}$ beyond hygiene, such as those outlined above. These will need to combine indicators that capture the detail of individual initiatives that can inform programme design, and those that can be aggregated to measure progress at higher levels across stakeholders.

Moving forward with holistic and inclusive approaches to $\mathrm{MH}$ at scale will not be solved by a single agency within a short-time frame. Stronger collaboration between sectors and stakeholders, and further research, will be needed to understand and overcome challenges and identify shared goals. Above all, there must be a willingness to learn from each other and to regularly listen to, and learn from, women and girls themselves in order to move forward with $\mathrm{MH}$ programming in Bangladesh.

\section{References}

Alam, S.S., Rahman, M.N., Mia, M.A., Haque, M.M. and Islam, K. (2018), "Reproductive health status and health seeking behavior of adolescent girls in selected urban slum of Dhaka City in Bangladesh", Global Journal of Reproductive Medicine, Vol. 5, pp. 1-6, doi: https://doi.org/10.19080/GJORM.2018.05.555669.

Alam, M.-U., Luby, S.P., Halder, A.K., Islam, K., Opel, A., Shoab, A.K., Ghosh, P.K., Rahman, M., Mahon, T. and Unicomb, L. (2017), "Menstrual hygiene management among Bangladeshi adolescent schoolgirls and risk factors affecting school absence: results from a cross-sectional survey", BMJ Open 7 , p. e015508, doi: https://doi.org/10.1136/bmjopen-2016-015508.

Asha, A.C., Karim, N.B., Bakhtiar, M. and Rahaman, K.S. (2019), "Adolescent athlete's knowledge, attitude and practices about menstrual hygiene management (MHM) in BKSP, Bangladesh", Asian Journal of Medical and Biological Research, Vol. 5 No. 2, pp. 126-137, doi: 10.3329/ajmbr. v5i2.42494.

Bangladesh Bureau of Statistics (2016), "Report on violence against women (VAW) survey 2015", available at: https://evaw-global-database.unwomen.org/-/media/files/un\%20women/vaw/vaw\%20survey/bangladesh\%20 vaw\%20survey\%202015.pdf?vs=2125 (accessed 27 November 2020). 
Bangladesh Bureau of Statistics (2017), "Education scenario in Bangladesh: gender perspective", available at: http://bbs.portal.gov.bd/sites/default/files/files/bbs.portal.gov.bd/page/4c7eb0f0_ e780_4686_b546_b4fa0a8889a5/BDcountry\%20project_final\%20draft_010317.pdf (accessed 24 November 2020).

Bobel, C. (2020), "Introduction: menstruation as lens - menstruation as opportunity", in Bobel, C., Winkler, I.T., Fahs, B., Hasson, K.A., Kissling, E.A. and Roberts, T.-A. (Eds), The Palgrave Handbook of Critical Menstruation Studies, Springer Singapore, Singapore, pp. 1-6, doi: 10.1007/978-981-15-0614-7_1.

Chandra-Mouli, V. and Patel, S.V. (2020), "Mapping the knowledge and understanding of menarche, menstrual hygiene and menstrual health among adolescent girls in low- and middle-income countries", in Bobel, C., Winkler, I.T., Fahs, B., Hasson, K.A., Kissling, E.A. and Roberts, T.-A. (Eds), The Palgrave Handbook of Critical Menstruation Studies, Springer Singapore, Singapore, pp. 609-636, doi: 10.1007/ 978-981-15-0614-7_46.

Erchull, M.J. (2020), "YYou will find out when the time is right': boys, men, and menstruation", in Bobel, C., Winkler, I.T., Fahs, B., Hasson, K.A., Kissling, E.A. and Roberts, T.-A. (Eds), The Palgrave Handbook of Critical Menstruation Studies, Springer Singapore, Singapore, pp. 395-407, doi: 10.1007/978-981-15-0614-7_31.

European Journalism Centre (2021), "Bangladesh television”, available at: https://medialandscapes.org/ country/bangladesh/media/television (accessed 24 November 2020).

Fahs, B. and Perianes, M.B. (2020), "Transnational engagement: designing an ideal menstrual health $(\mathrm{MH})$ curriculum - stories from the field”, in Bobel, C., Winkler, I.T., Fahs, B., Hasson, K.A., Kissling, E.A. and Roberts, T.-A. (Eds), The Palgrave Handbook of Critical Menstruation Studies, Springer Singapore, Singapore, pp. 449-465, doi: 10.1007/978-981-15-0614-7_35

Global South Coalition for Dignified Menstruation (2020), "December 8 Dignified Menstruation Day", available at: https://dignifiedmenstruation.org/mensturation-day/ (accessed 23 March 2020).

Guglielmi, S. Jones, N. Muz, J. Baird, S. Mitu, K. and Uddin, M.A. (2020), “'We didn't come here to eat. We came here to save our life': health and nutrition challenges facing adolescents in Cox's bazar, Bangladesh", available at: https://www.gage.odi.org/publication/we-didnt-come-here-toeat-we-came-here-to-save-our-life-health-and-nutrition-challenges-facing-adolescents-in-coxsbazar-bangladesh/ (accessed 27 November 2020).

Hennegan, J. (2020), "Interventions to improve menstrual health in low- and middle-income countries: do We know what works?", in Bobel, C., Winkler, I.T., Fahs, B., Hasson, K.A., Kissling, E.A. and Roberts, T.-A. (Eds), The Palgrave Handbook of Critical Menstruation Studies, Springer Singapore, pp. 637-652, doi: 10.1007/978-981-15-0614-7_47.

Hennegan, J. and Sol, L. (2020), "Confidence to manage menstruation at home and at school: findings from a cross-sectional survey of schoolgirls in rural Bangladesh", Culture, Health \& Sexuality, Vol. 22 No. 2, pp. 146-165, doi: 10.1080/13691058.2019.1580768.

Hennegan, J., Winkler, I.T., Bobel, C., Keiser, D., Hampton, J., Larsson, G., Chandra-Mouli, V., Plesons, M. and Mahon, T. (2021), "Menstrual health: a definition for policy, practice, and research", Sexual and Reproductive Health Matters, Vol. 29 No. 1, doi: 10.1080/26410397.2021.1911618.

ICDDR (2014), "Bangladesh national hygiene baseline survey: preliminary report. Dhaka, Bangladesh", ICDDR, b, Ministry of Local Government, Rural Development and Cooperatives, and WaterAid Bangladesh, available at: https://washmatters.wateraid.org/publications/bangladesh-national-hygienebaseline-survey-preliminary-report-2014 (accessed 17 November 2020).

International Women's Health Coalition (2019), "A shared agenda: exploring links between water, sanitation, hygiene, and sexual and reproductive health and rights in sustainable development", International Women's Health Coalition, Marie Stopes International, IPPF, Simavi and WaterAid, available at: www.msichoices.org/media/3673/a-shared-agenda. pdf (accessed 24 November 2020).

Johnston-Robledo, I. and Chrisler, J.C. (2020), "The menstrual mark: menstruation as social stigma", in Bobel, C., Winkler, I.T., Fahs, B., Hasson, K.A., Kissling, E.A. and Roberts, T.-A. (Eds), The Palgrave Handbook of Critical Menstruation Studies, Springer Singapore, Singapore, pp. 181-199, doi: 10.1007/ 978-981-15-0614-7_17.

Leavy, P. and Harris, A. (2019), Contemporary Feminist Research from Theory to Practice, Guildford Press, New York, NY, US.

Letherby, G. (2003), Feminist Research in Theory and Practice, Open University Press, UK. 
MacRae, E.R., Clasen, T., Dasmohapatra, M. and Caruso, B.A. (2019), “It's like a burden on the head': redefining adequate menstrual hygiene management throughout women's varied life stages in Odisha, India", Plos One, Vol. 14 No. 8, p. e0220114, doi: 10.1371/journal.pone.0220114.

Miller, V. and Winkler, I.T. (2020), "Transnational engagements: menstrual health and hygiene emergence and future directions", in Bobel, C., Winkler, I.T., Fahs, B., Hasson, K.A., Kissling, E.A. and Roberts, T.-A. (Eds), The Palgrave Handbook of Critical Menstruation Studies, Springer Singapore, Singapore, pp. 653-666, doi: 10.1007/978-981-15-0614-7_48.

Mondal, B.K. Ali, M.K. Dewan, T. and Tasnim, T. (2017), "Practices and effects of menstrual hygiene management in rural Bangladesh", Paper presented at the 40th WEDC Conference, 24-28 July, Loughborough, UK, available at: https://wedc-knowledge.Iboro.ac.uk/resources/conference/40/Mondal2578.pdf (accessed 27 November 2020)

National Institute of Population Research and Training and ICF (2019), "Bangladesh demographic and health survey 2017-18: key indicators", available at: https://dhsprogram.com/pubs/pdf/PR104/PR104. pdf (accessed 27 November 2020).

Patkar, A. (2020), "Policy and practice pathways to addressing menstrual stigma and discrimination", in Bobel, C., Winkler, I.T., Fahs, B., Hasson, K.A., Kissling, E.A. and Roberts, T.-A. (Eds), The Palgrave Handbook of Critical Menstruation Studies, Springer Singapore, Singapore, pp. 485-509, doi: 10.1007/ 978-981-15-0614-7_38.

Perianes, M.B. and Roberts, T.-A. (2020), "Transnational engagements: from debasement, disability, and disaster to dignity - stories of menstruation under challenging conditions", in Bobel, C., Winkler, I. T., Fahs, B., Hasson, K.A., Kissling, E.A. and Roberts, T.-A. (Eds), The Palgrave Handbook of Critical Menstruation Studies, Springer Singapore, Singapore, pp. 337-345, doi: 10.1007/978-981-15-06147_26.

Power, R., Wiley, K., Muhit, M., Heanoy, E., Karim, T., Badawi, N. and Khandaker, G. (2020), "Flower of the body: menstrual experiences and needs of young adolescent women with cerebral palsy in Bangladesh, and their mothers providing menstrual support", BMC Women's Health, Vol. 20 No. 1, p. 160, doi: 10.1186/s12905-020-01032-3.

Roaf, V. and de Albuquerque, C. (2020), "Practice note: why we started talking about menstruation looking back (and looking forward) with the UN special rapporteur on the human rights to water and sanitation", in Bobel, C., Winkler, I.T., Fahs, B., Hasson, K.A., Kissling, E.A. and Roberts, T.-A. (Eds), The Palgrave Handbook of Critical Menstruation Studies, Springer Singapore, Singapore, pp. 475-483, doi: 10.1007/978-981-15-0614-7_37.

Shannon, A.K., Melendez-Torres, G.J. and Hennegan, J. (2020), "How do women and girls experience menstrual health interventions in low- and middle-income countries? Insights from a systematic review and qualitative metasynthesis", Culture, Health \& Sexuality, Vol. 23 No. 5, pp. 1-20, doi: 10.1080/ 13691058.2020.1718758.

Simavi (2020), "Ritu programme final report: improving menstrual health of girls in Bangladesh", available at: https://simavi.org/wp-content/uploads/2020/09/Ritu-programme-final-report.pdf (accessed 24 November 2020).

Sultana, R., Shom, E.R. and Khatun, F. (2020), "Menstrual hygiene practice between rural and urban high school adolescent girls in Bangladesh", International Journal of Reproduction, Contraception, Obstetrics and Gynecology, Vol. 9 No. 3, pp. 1039-1044, doi: 10.18203/2320-1770.jjrcog20200871.

UN General Assembly (2018), "Resolution adopted by the Human Rights Council on 27 September 2018; 39/8 The human rights to safe drinking water and sanitation", available at: https://ap.ohchr.org/ documents/dpage_e.aspx?si=A/HRC/RES/39/8 (accessed 27 November 2020).

UNICEF (2020), "Guidance for monitoring menstrual health and hygiene", available at: https://washdata. org/report/unicef-2020-guidance-monitoring-mhh-v1 (accessed 27 November 2020).

Warrington, S. and Martin, J. (2017), "Moving forward: formative research to inform menstrual hygiene management programming in Bangladesh", unpublished, Plan International UK, London, UK.

WASH Sector Cox's Bazaar Inter Sector Coordination Group (2020), "Menstrual hygiene management (MHM) strategy", available at: https://reliefweb.int/sites/reliefweb.int/files/resources/ 200226_mhm_strategyand_kits_2020_final.pdf (accessed 24 November 2020).

Water Aid, Marie Stopes International Australia (2018), "Integrating menstrual health, water, sanitation and hygiene, and sexual and reproductive health in Asia and the Pacific region: a discussion paper", available 
at: https://washmatters.wateraid.org/publications/integrated-approaches-to-menstrual-health-in-asia-andthe-pacific (accessed 27 November 2020).

Zakaria, M., Karim, F., Mazumder, S., Cheng, F. and Xu, J. (2020), "Knowledge on, attitude towards, and practice of sexual and reproductive health among older adolescent girls in Bangladesh: an institutionbased cross-sectional study", International Journal of Environmental Research and Public Health, Vol. 17 No. 21, p. 7720, doi: 10.3390/ijerph17217720.

\section{Further reading}

Coultas, M., Martin, J., Stephen, C. and Warrington, S. (2017), "Moving forward: findings from menstrual hygiene management formative research in Bangladesh", Paper presented at the 40th WEDC Conference, 24-28 July, Loughborough, UK, available at: https://wedc-knowledge.lboro.ac.uk/ resources/conference/40/Coultas-2783. pdf (accessed 27 November 2020).

Equal Measures 2030 (2019), "Harnessing the power of data for gender equality: introducing the 2019 EM2030 SDG gender index", available at: www.equalmeasures2030.org/wp-content/uploads/2019/07/ EM2030_2019_Global_Report_English_WEB.pdf (accessed 17 November 2020).

Loughnan, L., Mahon, T., Goddard, S., Bain, R. and Sommer, M. (2020), "Monitoring menstrual health in the sustainable development goals", in Bobel, C., Winkler, I.T., Fahs, B., Hasson, K.A., Kissling, E.A. and Roberts, T.-A. (Eds), The Palgrave Handbook of Critical Menstruation Studies, Springer Singapore, Singapore, pp. 577-592, doi: 10.1007/978-981-15-0614-7_44.

Schmitt, M.L. Wood, O.R. Clatworthy, D. Rashid, S.F. and Sommer, M. (2020), "Innovative strategies for providing Menstruation-Supportive water, sanitation and hygiene (wash) facilities: learning from refugee camps in cox's bazar, Bangladesh (preprint)", In Review, doi: 10.21203/rs.3.rs-45341/v1.

WASH United (2021), "Significant new language on MHM in human rights council resolution a/HRC/39/ L.11", available at: https://menstrualhygieneday.org/significant-new-language-mhm-human-rightscouncil-resolution-ahrc39l-11/ (accessed 17 November 2020).

Water Aid (2020), "Menstrual health and hygiene: challenges associated with the COVID-19 pandemic in Bangladesh", available at: www.wateraid.org/bd/publications/menstrual-health-and-Hygiene (accessed 27 November 2020).

WHO (1948), "Preamble to the constitution of WHO as adopted by the international health conference, New York", 19 June-22 July 1946; signed on 22 July 1946 by the representatives of 61 States (Official Records of WHO, no. 2, p. 100) and entered into force on 7 April 1948.

\section{About the authors}

Siobhan Warrington is a Senior Research Associate with Newcastle University's Oral History Unit and Collective, currently working on the Living Deltas Research Hub. She has over 25 years' experience of collaborating with civil society across the globe to record and communicate the expertise and experiences of those living with poverty, HIV, environmental change and displacement. She has undertaken research for many international NGOs, including a substantial body of work on ethical image making. She has also led several research projects on women and girls' safety, health and rights. She is editor of the International Work section of the Oral History Journal. Siobhan Warrington is the corresponding author and can be contacted at: siobhan.warrington@newcastle.ac.uk

Mimi Coultas is a sanitation and hygiene specialist currently working as a Research Officer with the Sanitation Learning Hub at the Institute of Development Studies, University of Sussex. Prior this, she spent ten years working for a range of national and international NGOs designing and implementing water, sanitation and hygiene programmes across Africa and Asia. She is particularly interested in participatory approaches to support timely, relevant and actionable learning on areas including gender equality, inclusion and behaviour change, both within and beyond the sanitation and hygiene sector.

Mitali Das is a young professional from Bangladesh with more than eight years of extensive experience in the development and media and communications sectors. Her areas of expertise are gender, gender-based violence, sexual and reproductive health and rights and menstrual health. At the time of writing this article, she was working as a 
communications expert at one of Bangladesh' most reputed human rights and legal aid organisations. She also volunteers with various local and international charitable organisations to provide education to underprivileged children.

Effat Nur is a researcher and behaviour change communication specialist currently working with Plan International Bangladesh. She holds both bachelor's and master's degrees in Social Anthropology from Rajshahi University. She has experience of coordinating both quantitative and qualitative research for both NGOs and government departments. She is particularly interested in understanding the experiences of women and girls and working to improve their lives.

For instructions on how to order reprints of this article, please visit our website: www.emeraldgrouppublishing.com/licensing/reprints.htm

Or contact us for further details: permissions@emeraldinsight.com 